\title{
PENGARUH FUNGI MIKORIZA ARBUSKULA DAN PUPUK KANDANG TERHADAP SERAPAN HARA KACANG HIJAU (Phaseolus radiatus L.) PADA ULTISOL
}

\author{
(The Effect of arbuscular mycorrhizal fungi And manure on green been (Phaseolus \\ radiatus L.) Nutrient Uptake on Ultisol)
}

\author{
Juliani Anata Lubis ${ }^{1}$, Fikrinda ${ }^{1}$, Hifnalisa ${ }^{1^{*}}$ \\ ${ }^{1}$ Program Studi Ilmu Tanah, Fakultas Pertanian, Universitas Syiah Kuala \\ Corresponding author: hifnalisa@unsyiah.ac.id
}

\begin{abstract}
Abstrak. Pemanfaatan fungi mikoriza arbuskular (FMA) dan pupuk kandang merupakan teknologi untuk meningkatkan produktivitas tanaman pada ultisol. Penelitian ini bertujuan untuk mengetahui pengaruh FMA dan pupuk kandang terhadap serapan hara N, P, K. Penelitian ini menggunakan Rancangan Acak Kelompok (RAK) pola faktorial $2 \times 3$ dengan 4 kelompok. Faktor yang dicobakan adalah FMA dan pupuk kandang kambing. Faktor pertama adalah FMA (Fungi Mikoriza Arbuskula) dengan 2 taraf yaitu: M $_{0}$ : Tanpa FMA dan $M_{1}$ Aplikasi FMA: 20 g/polibag. Faktor kedua yaitu pupuk kandang yang terdiri dari 3 taraf yaitu: $\mathrm{P}_{0}$ : tanpa pupuk kandang, $\mathrm{P}_{1}: 50 \mathrm{~g} /$ polibag pupuk kandang, $\mathrm{P}_{2}: 100 \mathrm{~g} /$ polibag pupuk kandang. Adapun hasil penelitian menunjukkan bahwa serapan $\mathrm{N}$ sangat nyata dipengaruhi oleh FMA, namun tidak nyata oleh perlakuan pupuk kandang dan interaksi FMA dan pupuk kandang, serapan P sangat nyata dipengaruhi oleh FMA, namun tidak nyata oleh perlakuan pupuk kandang dan interaksi FMA dan pupuk kandang serta serapan $\mathrm{K}$ sangat nyata dipengaruhi oleh FMA, namun tidak nyata oleh perlakuan pupuk kandang dan interaksi FMA dan pupuk kandang. Inokulalasi FMA dengan pemberian $100 \mathrm{~g} /$ polibag pupuk kandang kambing memberikan pengaruh terbaik terhadap perbaikan serapan hara kacang hijau pada ultisol.
\end{abstract}

\section{Kata Kunci : Mikoriza, Pupuk Kandang, Serapan Hara, Kacang Hijau, Ultisol}

Abstract. The use of arbuscular mycorrhizal fungi and manure is a technology to increase plant productivity on ultisols. This study aims to determine the effect of AMF and manure on nutrient uptake of $\mathrm{N}, \mathrm{P}, \mathrm{K}$. This study used a $2 \times 3$ factorial randomized block design with 4 groups. The factors tested were AMF and manure. The first factor is AMF (Arbuscular Mycorrhizal Fungi) with 2 levels, namely: M0: Without AMF and M1 Application of AMF: $20 \mathrm{~g} /$ polybag. The second factor is manure which consists of 3 levels, namely: P0: without manure, P1: $50 \mathrm{~g} /$ polybags of manure, P2: $100 \mathrm{~g} /$ polybags of manure. The results showed that $\mathrm{N}$ uptake was significantly influenced by AMF, but not significantly by manure treatment and the interaction of AMF and manure, $\mathrm{P}$ uptake was significantly influenced by AMF, but not significantly by manure treatment and the interaction between AMF and manure and $\mathrm{K}$ uptake was significantly affected by AMF, but not significantly by manure treatment and the interaction between AMF and manure. AMF inoculation by giving $100 \mathrm{~g} /$ polybag of goat manure gave the best effect on improving the nutrient uptake of green beans on ultisols.

Keywords : Mycorrhiza, Manure, Nutrient Uptake, Green beans, Ultisol 


\title{
PENDAHULUAN
}

Kacang hijau merupakan tanaman terpenting yang setiap tahunnya mengalami penurunan produksi akibat penurunan kualitas maupun kuantitas lahan. Adapun hal yang dapat kita lakukan ialah dengan meningkatkan penggunaan Ultisol dengan memanfaatkan fungi mikoriza arbuskular dan pupuk kandang.

Aplikasi fungi mikoriza arbuskula dan pupuk kandang merupakan upaya-upaya yang banyak dilaporkan efektif meningkatkan produktivitas tanah dan tanaman di lahan suboptimal. fungi mikoriza arbuskula merupakan golongan fungi yang memiliki hubungan simbiosis mutualisme yaitu hubungan yang saling menguntungkan antara tanaman dan fungi. (Diastama et al., 2015). Peranan mikoriza dalam menjaga keragaman hayati dan ekosistem sekarang mulai dikenal, terutama sekali karena pengaruh mikoriza untuk mempertahankan keanekaragaman tumbuhan dan meningkatkan produktivitasnya (Pulungan, 2013).

Pupuk kandang adalah pupuk yang berasal dari kotoran hewan, berupa kotoran padat dan air seni serta sisa-sisa makanan dan alas kandang. Pemberian pupuk kandang dapat meningkatkan daya serap air serta dapat meningkatkan aktivitas biologi tanah dimana dalam hal ini organisme tanah sangat berperan dalam merubah bahan organik sehingga menjadi bentuk senyawa lain sehingga bermanfaat bagi kasuburan tanah (Arifah, 2013). Penelitian ini dilakukan dengan pemberian FMA dan pupuk kandang diharapkan dapat meningkatkan penyerapan unsur hara dan mampu menyumbang ketersediaan unsur hara pada tanah.

\section{METODE PENELITIAN}

\section{Tempat dan Waktu Penelitian}

Penelitian ini dilakukan di kebun percobaan Fakultas Pertanian Universitas Syiah Kuala. Analisis sampel tanah dan hara tanaman dilakukan di Laboratorium Tanah dan Tanaman Fakultas Pertanian Universitas Syiah Kuala dan analisis kolonisasi akar dilakukan di Laboratorium Biologi Tanah Fakultas Pertanian Universitas Syiah Kuala. Penelitian ini dilaksanakan pada Januari sampai dengan April 2019.

\begin{abstract}
Alat dan Bahan
Alat-alat yang digunakan pada penelitian ini adalah saringan ukuran $5 \mathrm{~mm}$, mikroskop cahaya, timbangan analitik, cangkul, pisau cutter, gayung, oven, mistar, kamera dan alat-alat gelas yang digunakan untuk analisis di laboratorium.

Bahan-bahan yang digunakan adalah benih kacang hijau Varietas Vima 3, bahan tanah Ultisol, polibag ukuran 25 x $25 \mathrm{~cm}$, Urea, TSP, KCl, amplop kertas, larutan $\mathrm{KOH} \mathrm{10 \% ,} \mathrm{HCl}$ $1 \%$, tinta Quinck Parker biru, inokulum FMA campuran (Acaulospora tuberculata dan Gigaspora cf gigantea) koleksi Dr. Ir. Fikrinda, M.Si, pupuk kandang kambing, serta bahanbahan kimia untuk analisis di laboratorium.
\end{abstract}

\section{Rancangan Percobaan}

Penelitian ini menggunakan Rancangan Acak Kelompok (RAK) pola faktorial 2 x 3 dengan 4 kelompok. Faktor yang dicobakan adalah FMA (tanpa FMA dan 20 g/polibag FMA) dan pupuk kandang (tanpa pupuk kandang; $50 \mathrm{~g} /$ polibag pupuk kandang; dan $100 \mathrm{~g} /$ polibag pupuk kandang. 


\section{Persiapan Media Tanam}

Bahan tanah yang digunakan sebagai media tanam adalah Ultisol yang berasal dari Desa Teureubeh Kecamatan Jantho Kabupaten Aceh Besar.

\section{Aplikasi Pupuk Kandang}

Pupuk kandang yang digunakan pada penelitian ini adalah pupuk kandang kambing. Pupuk kandang yang digunakan terlebih dahulu dibersihkan dari kotoran plastik dan batu, kemudian ditimbang sesuai dengan dosis yang diperlukan dan dimasukkan pada media tanam yang sudah dipolibag untuk diinkubasi selama 14 hari. Sebagian sampel pupuk kandang tersebut dilakukan analisis kimianya yang bertujuan untuk mengetahui sifat kimia pupuk kandang yang digunakan.

\section{Inokulasi Fungi Mikoriza Arbuskula}

Inokulan FMA yang digunakan terdiri atas spora FMA campuran (Acaulospora tuberculata dan Gigaspora cf gigantea), hifa, akar yang terkolonisasi FMA, dan media pembawa zeolit+pasir. Inokulan FMA sesuai perlakuan ditempatkan di lubang tanam saat penanaman benih kacang hijau.

\section{Penanaman Benih Kacang Hijau}

Benih kacang hijau sebanyak tiga benih ditanam pada lubang tanam di atas inokulan FMA sesuai perlakuan. Setelah tanaman berumur tujuh hari hanya satu bibit yang dirawat sampai akhir percobaan sedangkan dua tanaman lainnya dipangkas dan dibenamkan di dalam polibag percobaan.

\section{Pemeliharaan Tanaman}

Pemeliharaan ditujukan agar tanaman tetap dalam kondisi baik selama masa pertumbuhan. Adapun pemeliharaan yang dilakukan meliputi:

1. Penyiraman

Penyiraman dilakukan dua kali sehari yaitu pada pagi dan sore hari, namun apabila kondisi lembab maka penyiraman dilakukan satu kali dalam satu hari. Penyiraman dilakukan menggunakan gayung. Penyiraman dilakukan dari awal penanaman hingga panen.

2. Pemupukan

Pemupukan dasar dilakukan pada saat awal penanaman dengan $75 \%$ dosis anjuran yaitu Urea 187,5 kg/ha (1 g/polibag), TSP $75 \mathrm{~kg} / \mathrm{ha}(0,4 \mathrm{~g} /$ polibag) dan $\mathrm{KCl} 112,5 \mathrm{~kg} / \mathrm{ha}$ (0,6 g/polibag). Pemupukan Urea dilakukan 2 kali yaitu setengah dosis pada awal penanaman kemudian pada umur 36 hari setelah tanam, sedangkan TSP dan $\mathrm{KCl}$ diberikan pada saat menanam. Pupuk diberikan dilingkaran lubang benih yang ditanam.

3. Penyiangan

Penyiangan dilakukan dengan cara manual, yaitu mencabut gulma dengan tangan secara perlahan. 
4. Pembumbunan

Pembumbunan dilakukan pada saat tanaman telah berumur satu bulan setelah tanam, tujuan dilakukan pembumbunan agar tanaman dapat berdiri tegak dan kokoh sehingga tidak mudah rubuh terutama saat tertiup angin.

5. Pengendalian Hama

Pengendalian hama dilakukan apabila terdapat serangan hama pada tanaman kacang hijau, maka dilakukan pengendalian dengan cara manual yaitu dengan cara mengambilnya dari tanaman menggunakan tangan kemudian membuangnya.

\section{Serapan Hara}

Serapan hara N, P dan K dihitung per hektar menggunakan asumsi jumlah tanaman per hektar. Perhitungan serapan hara tanaman dilakukan pada saat tanaman fase vegetatif maksimal atau pada umur $36 \mathrm{HST}$. Analisis unsur hara N dilakukan dengan metode Kjeldahl, sedangkan unsur $\mathrm{P}$ dan $\mathrm{K}$ diekstrak dengan metode pengabuan basah. Sampel tanaman yang diambil adalah seluruh bagian tanaman. Pengukuran kadar serapan hara dilakukan dengan menggunakan spektrofotometer pada panjang gelombang $420 \mu \mathrm{m}$. Berdasarkan Fitter dan Hay (1998) nilai serapan hara dihitung dengan rumu :

Serapan Hara = Kadar Hara x Berat Kering Tanaman x Jumlah Tanaman per Ha

\section{HASIL DAN PEMBAHASAN}

\section{Serapan Hara N}

Hasil penelitian menunjukkan bahwa serapan $\mathrm{N}$ sangat nyata dipengaruhi oleh FMA, namun tidak nyata oleh perlakuan pupuk kandang dan interaksi FMA dan pupuk kandang. Rata-rata serapan hara $\mathrm{N}$ akibat fungi mikoriza arbuskula dan pupuk kandang tersaji pada Tabel 1.

Tabel 1. Rata-rata Serapan Hara N pada Kacang Hijau Akibat Fungi Mikoriza Arbuskula dan Pupuk Kandang.

\begin{tabular}{|c|c|c|c|c|}
\hline & \multicolumn{3}{|c|}{ Pupuk Kandang } & \multirow[b]{2}{*}{ Rata-rata } \\
\hline $\begin{array}{l}\text { Inokulan } \\
\text { FMA (g) }\end{array}$ & $\begin{array}{r}0 \mathrm{~g} / \\
\text { polibag } \\
\left(\mathrm{P}_{0}\right)\end{array}$ & $\begin{array}{r}50 \mathrm{~g} / \\
\text { polibag }\left(\mathrm{P}_{1}\right)\end{array}$ & $\begin{array}{r}100 \mathrm{~g} / \\
\text { polibag }\left(\mathrm{P}_{2}\right)\end{array}$ & \\
\hline \multicolumn{5}{|c|}{$\mathrm{Kg} \mathrm{ha}^{-1}$} \\
\hline Tanpa FMA & 65,95 & 82,03 & 119,75 & $89,24 a$ \\
\hline FMA & 201,71 & 163,90 & 193,23 & $186,28 b$ \\
\hline Rata-rata & 133,83 & 122,97 & 156,49 & \\
\hline
\end{tabular}

Keterangan : Angka yang Diikuti Huruf yang Sama pada Kolom yang Sama Tidak Berbeda Nyata pada Taraf $5 \%\left(\mathrm{BNT}_{0,05}=36,48\right)$.

Serapan hara $\mathrm{N}$ akibat perlakuan tanpa FMA $\left(\mathrm{M}_{0}\right)$ berbeda nyata dengan diberi FMA $\left(\mathrm{M}_{1}\right)$ terhadap serapan hara $\mathrm{N}$. Hal ini dikarenakan akar tanaman bersimbiosis dengan 
mikoriza sehingga mampu meningkatkan serapan hara N. Harahap et al. (2018) menyatakan mikoriza mampu meningkatkan perluasan bidang serapan air dan hara, dengan menggunakan hifa-hifa yang halus sehingga memungkinkan dapat menyerap air lebih besar pada tanaman bermikoriza, serapan air yang lebih besar oleh tanaman bermikoriza akan membawa unsur hara yang mudah larut seperti $\mathrm{N}$ sehingga serapan hara meningkat.

Serapan hara $\mathrm{N}$ akibat pemberian pupuk kandang $100 \mathrm{~g} /$ polibag yang dijumpai dengan rata-rata tertinggi dibandingkan dengan pemberian pupuk kandang $50 \mathrm{~g} /$ polibag dan tanpa pupuk kandang. Pemberian pupuk kandang $100 \mathrm{~g} /$ polibag dapat meningkatkan serapan hara $\mathrm{N}$ sebesar $16,93 \%$ dibandingkan tanpa pupuk kandang. Hal ini diduga karena penambahan pupuk kandang mampu meningkatkan hara N pada tanah. Menurut Makka et al. (2015) penambahan pupuk kandang dapat meningkatkan $\mathrm{N}$ total tanah, sehingga kebutuhan hara $\mathrm{N}$ tanaman bisa terpenuhi.

\section{Serapan Hara P}

Hasil penelitian menunjukkan bahwa serapan P sangat nyata dipengaruhi oleh FMA, namun tidak nyata oleh perlakuan pupuk kandang dan interaksi FMA dan pupuk kandang. Rata-rata serapan hara $\mathrm{P}$ akibat inokulasi fungi mikoriza arbuskula dan pupuk kandang tersaji pada Tabel 2.

Tabel 2. Rata-rata Serapan Hara P pada Kacang Hijau Akibat Fungi Mikoriza Arbuskula dan Pupuk Kandang.

\begin{tabular}{|c|c|c|c|c|}
\hline \multirow[b]{2}{*}{ Inokulan } & \multicolumn{3}{|c|}{ Pupuk Kandang } & \multirow[b]{2}{*}{ Rat } \\
\hline & $0 \mathrm{~g} /$ & 50 & 100 & \\
\hline FMA (g) & polibag & g/polibag & g/polibag & a-rata \\
\hline & $\left(\mathrm{P}_{0}\right)$ & $\left(\mathrm{P}_{1}\right)$ & $\left(\mathrm{P}_{2}\right)$ & \\
\hline \multicolumn{5}{|c|}{$\mathrm{Kg} \mathrm{ha}^{-1}$} \\
\hline Tanpa & 2670 & 4453 & 1730 & 3051 \\
\hline FMA & 20,10 & 44,J5 & $4 /, 50$ & 39, , \\
\hline FMA & 76,07 & 66,90 & 86,64 & $76,54 b$ \\
\hline Rata-rata & 51,39 & 55,72 & 66,97 & \\
\hline
\end{tabular}

Keterangan : Angka yang Diikuti Huruf yang Sama pada Kolom yang Sama Tidak Berbeda Nyata pada Taraf $5 \%\left(\mathrm{BNT}_{0,05}=22,18\right)$.

Serapan hara P akibat perlakuan tanpa FMA $\left(\mathrm{M}_{0}\right)$ berbeda nyata dengan diberi FMA $\left(\mathrm{M}_{1}\right)$ terhadap serapan hara P. Pemberian FMA dapat meningkatkan serapan hara P sebesar 93,73\%. Hal ini disebabkan karena FMA merupakan jamur yang sangat aktif dan berperan dalam melepaskan hara $\mathrm{P}$ yang tidak tersedia bagi tanaman sehingga tersedia bagi tanaman melalui pemanjangan hifa. Menurut Jannah (2011) Mikoriza dapat membebaskan unsur P dari Al serta dapat meningkatkan dan memperluas bidang serapan akar tanaman. Hal ini sejalan dengan Fitriatin et al. (2014) menyatakan bahwa pemberian FMA dapat meningkatkan serapan hara P tanaman kacang hijau pada tanah Ultisol. 
Serapan hara $\mathrm{P}$ akibat pemberian pupuk kandang $100 \mathrm{~g} /$ polibag dijumpai dengan ratarata tertinggi dibandingkan dengan pemberian pupuk kandang $50 \mathrm{~g} /$ polibag dan tanpa pupuk kandang. Hal ini diduga karena pupuk kandang yang digunakan mampu meningkatkan ketersedian hara $\mathrm{P}$ yang dapat dilihat berdasarkan rataan menunjukkan pemberian pupuk kandang mengalami kenaikan disetiap perlakuannya yaitu pupuk kandang $50 \mathrm{~g} /$ polibag meningkatkan serapan hara $\mathrm{P}$ sebesar 8,44\% dan pemberian pupuk kandang $100 \mathrm{~g} / \mathrm{polibag}$ meningkatkan serapan hara $\mathrm{P}$ sebesar $30,33 \%$ dibanding tanpa pemberian pupuk kandang. Menurut Alfandi et al. (2015) menyatakan bahwa pemberian pupuk kandang berupa kotoran kambing akan meningkatkan serapan hara $\mathrm{P}$ tanaman secara nyata.

\section{Serapan Hara K}

Hasil penelitian menunjukkan bahwa serapan K sangat nyata dipengaruhi oleh FMA, namun tidak nyata oleh perlakuan pupuk kandang dan interaksi FMA dan pupuk kandang. Rata-rata serapan hara $\mathrm{K}$ akibat inokulasi fungi mikoriza arbuskula dan pupuk kandang tersaji pada Tabel 3.

Tabel 3. Rata-rata Serapan Hara K Pada Kacang Hijau Akibat Inokulasi Fungi Mikoriza Arbuskula dan Pupuk Kandang.

\begin{tabular}{|c|c|c|c|c|}
\hline \multirow{4}{*}{$\begin{array}{l}\text { Inokulan } \\
\text { FMA } \\
\text { (g) }\end{array}$} & \multicolumn{3}{|c|}{ Pupuk Kandang } & \multirow{4}{*}{$\begin{array}{l}\text { Rata- } \\
\text { rata }\end{array}$} \\
\hline & $0 \mathrm{~g} /$ & 50 & 100 & \\
\hline & polybag & g/polybag & g/polybag & \\
\hline & $\left(\mathrm{P}_{0}\right)$ & $\left(\mathrm{P}_{1}\right)$ & $\left(\mathrm{P}_{2}\right)$ & \\
\hline \multicolumn{5}{|c|}{$\mathrm{Kg} \mathrm{ha}^{-1}$} \\
\hline Tanpa FMA & 259,80 & 351,28 & 388,03 & $333,04 a$ \\
\hline FMA & 628,21 & 560,69 & 797,23 & $662,04 b$ \\
\hline Rata-rata & 444,01 & 444,01 & 455,99 & \\
\hline
\end{tabular}

Keterangan : Angka yang Diikuti Huruf yang Sama pada Kolom yang Sama Tidak Berbeda Nyata pada Taraf $5 \%\left(\mathrm{BNT}_{0,05}=156,24\right)$.

Serapan hara K akibat perlakuan tanpa FMA $\left(\mathrm{M}_{0}\right)$ berbeda nyata dengan diberi FMA $\left(\mathrm{M}_{1}\right)$ terhadap serapan hara K. Pemberian FMA dapat meningkatkan serapan hara $\mathrm{K}$ sebesar 98, 78\%. Hal ini disebabkan karena terjadi korelasi antara FMA dan tingkat infeksi pada akar tanaman. Inokulasi fungi mikoriza arbuskular pada tanaman kedelai akan memberikan respon yang menguntungkan, dimana mikoriza akan meningkatkan infeksi akar dan membentuk jalinan hifa-hifa mikoriza, sehingga dapat memperluas bidang serapan hara dalam tanah (Jannah, 2011). Hal ini sejalan dengan Hartoyo et al., (2015) menyatakan bahwa pemberian FMA dapat meningkatkan serapan hara $\mathrm{K}$ sebesar 4,2\% dari pada tanpa aplikasi FMA.

Serapan hara K akibat pemberian pupuk kandang $100 \mathrm{~g} /$ polibag yang dijumpai dengan rata-rata tertinggi dibandingkan dengan pemberian pupuk kandang $50 \mathrm{~g} /$ polibag dan tanpa pupuk kandang. Hal ini diduga pupuk kandang yang memiliki koloid organik bermuatan negatif mampu mengikat hara $\mathrm{K}$ sehingga tersedia bagi tanaman yang dapat dilihat berdasarkan rataan menunjukkan pemberian pupuk kandang mengalami kenaikan disetiap 
perlakuannya yaitu pupuk kandang $50 \mathrm{~g} /$ polibag meningkatkan serapan hara K sebesar 2,70 \% dan pemberian pupuk kandang 100 g/polibag meningkatkan serapan hara $\mathrm{K}$ sebesar $33,47 \%$ dibanding tanpa pemberian pupuk kandang. Menurut Kuncoro (2008) pupuk kandang merupakan pupuk organik yang memiliki peranan dalam menyediakan unsur $\mathrm{K}$ untuk tanaman yakni melalui mineralisasi bahan organik dan memasok hara $\mathrm{K}$ serta kandungan koloid organik yang bermuatan negatif akan mengikat hara K sehingga Unsur K pada pupuk kandang akan diserap secara maksimal oleh tanaman.

\section{KESIMPULAN}

Inokulasi fungi mikoriza arbuskula nyata terhadap peningkatan serapan hara $\mathrm{N}, \mathrm{P}, \mathrm{K}$ dan pupuk kandang tidak nyata terhadap peningkatan serapan hara $\mathrm{N}, \mathrm{P}, \mathrm{K}$ serta Interaksi antara FMA dan pupuk kandang tidak nyata terhadap peningkatan serapan hara N, P, K.

\section{DAFTAR PUSTAKA}

Alfandi, F. N., B. Siswanto dan Y, Nuraini. 2015. Pengaruh pemberian berbagai jenis bahan organik terhadap sifat kimia tanah pada pertumbuhan dan produksi tanaman ubi jalar di Entisol Ngrangkah Pawon, Kediri. Tanah dan Sumberdaya Lahan. 2(2): 237-244.

Arifah, S. M. 2013. Aplikasi macam dan dosis pupuk kandang pada tanaman kentang. Gamma. 8(2): 80-85.

Diastama, W. P., G. K. Susrama dan G. P. Wirawan. 2015. Isolasi dan karakterisasi fungi mikoriza arbuskula pada tanah dan akar tanaman jagung di desa Sanur Kaja. Agroekoteknologi Tropika. 4(1): 66-73.

Fitriatin, B. N., A. Yuniarti., T. Turmuktini dan F. K. Ruswandi. 2014. The Effect of Phosphate Solubilizing Microbe Producing Growth Regulators on Soil Phosphate, Growth and Yield of Maize and Fertilizer Efficiency on Ultisol. Eurasian J. of Soil Sci. Indonesia. Hal:101-107.

Harahap, L. H., A. S. Hanafiah dan H. Guchi. 2018. Efektivitas pemberian mikoriza terhadap serapan hara $\mathrm{N}$ dan $\mathrm{P}$ tanaman karet pada lahan dengan cekaman kekeringan yang telah diberi bahan organik. Agroekoteknologi. 6(1): 167-173.

Hartoyo, B., O. Trisilawati dan M. Ghulamahdi. 2015. Tanggap pertumbuhan dan biomasa pegangan (Centella asiatica. L Urban) pada aplikasi fungi mikoriza arbuskular dan pemupukan di Andosol. Bul littro. 26 (6): 87-96.

Jannah, H. 2011. Respon tanaman kedelai terhadap asosiasi fungsi mikoriza arbuskular di lahan kering. Ganec Swara. 5(2): 28-31.

Kuncoro, H. 2008. Serapan hara P dan K serta hasil tanaman padi pada berbagai imbangan pupuk kandang dan pupuk anorganik di lahan sawah Palur Sukoharjo. Skripsi. Universitas Sebelas Maret. Surakarta.

Makka, A. A., Y. S. Patadungan dan S. W. Prahastuti. 2015. Pengaruh pupuk kandang ayam terhadap serapan hara nitrogen oleh tanaman kubis bunga pada oxid dystrudepts lembantongoa. Agroland. 22(2): 138-146.

Pulungan, A. S. S. 2013. Infeksi fungi mikoriza arbuskular pada tanaman tebu (Saccharum $\begin{array}{llll}\text { officinarum). } & \text { Biosains } & \text { Unimed. } & \text { 1(1): }\end{array}$ 